\title{
El Katak de Rafael Spregelburd y el triunfo del habla sin lengua.
}

\author{
(4) María Victoria Coce \\ Universidad Nacional de las Artes - Universidad de Buenos Aires, Argentina \\ viasensus@hotmail.com
}

Fecha de recepción: 23/10/2018. Fecha de aceptación: 11/02/2019.

\begin{abstract}
Resumen
El trabajo analiza La Terquedad de Rafael Spregelburd a partir de la interpretación de la noción de terquedad como ese sin sentido de Planc de buscar obstinadamente un sentido a través de la invención de una lengua artificial, numérica y universal que anule las diferencias, basada en el anhelo del protagonista de devolverle a los hombres la facultad primitiva que Dios le dio al hombre de un habla sin lengua. Nuestra investigación se basa en un análisis de la organización temporal de los hechos en la trama, la cual se inicia y termina con el hombre primitivo, con la negación de la lengua, también de la artificial inventada por Planc, ese alfabeto numérico propuesto como solución a la multiplicación caprichosa que cada idioma hace de sus palabras. Entendemos que la obra descansa sobre una estructuración circular de la fábula que reproduce la terquedad del protagonista y contribuye a resaltar una noción de lenguaje sin relación con el mundo, un lenguaje vuelto sobre sí mismo.
\end{abstract}

\section{The Katak by Spregelburd and the Triumph of a Speech without Language}

\footnotetext{
Astract

The paper analyzes Rafael Spregelburd's La Terquedad (The Stubbornness) based on an interpretation of the notion of stubbornness as Planc's nonsense of stubbornly pursuiting sense through the invention of an artificial, numerical and universal language that cancels the differences, supported on the protagonist's desire to give back to men that primitive faculty that God once gave them of a speech without language. Our investigation is based on an analysis of the temporal organization of facts in the play's plot, which begins and ends with the primitive man, with the negation of language; even of the artificial one invented by Planc: that numerical alphabet proposed as a solution to the capricious multiplication of its own words
}

Palabras clave

Spregelburd La Terquedad La mesa de los pecados capitales Katak

Keywords

Spregelburd La Terquedad The deadly sins's table Katak 
carried out by each language. We understand that the play rests on a circular structuring of the fable that reproduces the stubbornness of the protagonist and helps to highlight a notion of language without relation to the world, a language turned on itself.

El Katak es el lenguaje que en La Terquedad inventa Jaume Planc, el comisario fascista que vive en las afueras de Valencia en los tiempos finales de la guerra civil española. La obra, estrenada en la bienal de Frankfurter Positionen (Alemania), fue puesta en escena en 2107 en el Teatro Nacional Cervantes ${ }^{1}$ y es la última pieza de la famosa Heptalogía de Hieronymus Bosch de Rafael Spregelburd (La inapetencia-1996-, La extravagancia -1997-, La modestia -1999-, La estupidez-2001-, El pánico-2002-, La paranoia -2006- y La terquedad-2007-), conjunto que el mismo autor concibe como un proyecto artístico basado en una recreación teatral de la obra del pintor flamenco de La mesa de los pecados capitales. Y como el mismo Spregelburd dice "en el conjunto de mi modesta Hetpalogía no está Dios. Está -creo yo- el lenguaje (...) creo que es justo que en ese ojo vacío que está en el centro ubique al lenguaje" (Spregelburd, en Sophie Gander 2008: 167). En efecto, en el centro compositivo del cuadro de El Bosco está Cristo resucitado y mostrando sus estigmas. La pintura es una suerte de tabla de valores o disvalores morales, en donde el centro es el punto de partida y de llegada, el punto de referencia donde los pecados se alejan del centro que advierte: cave, cave Deus videt (ten cuidado, ten cuidado, Dios lo ve).

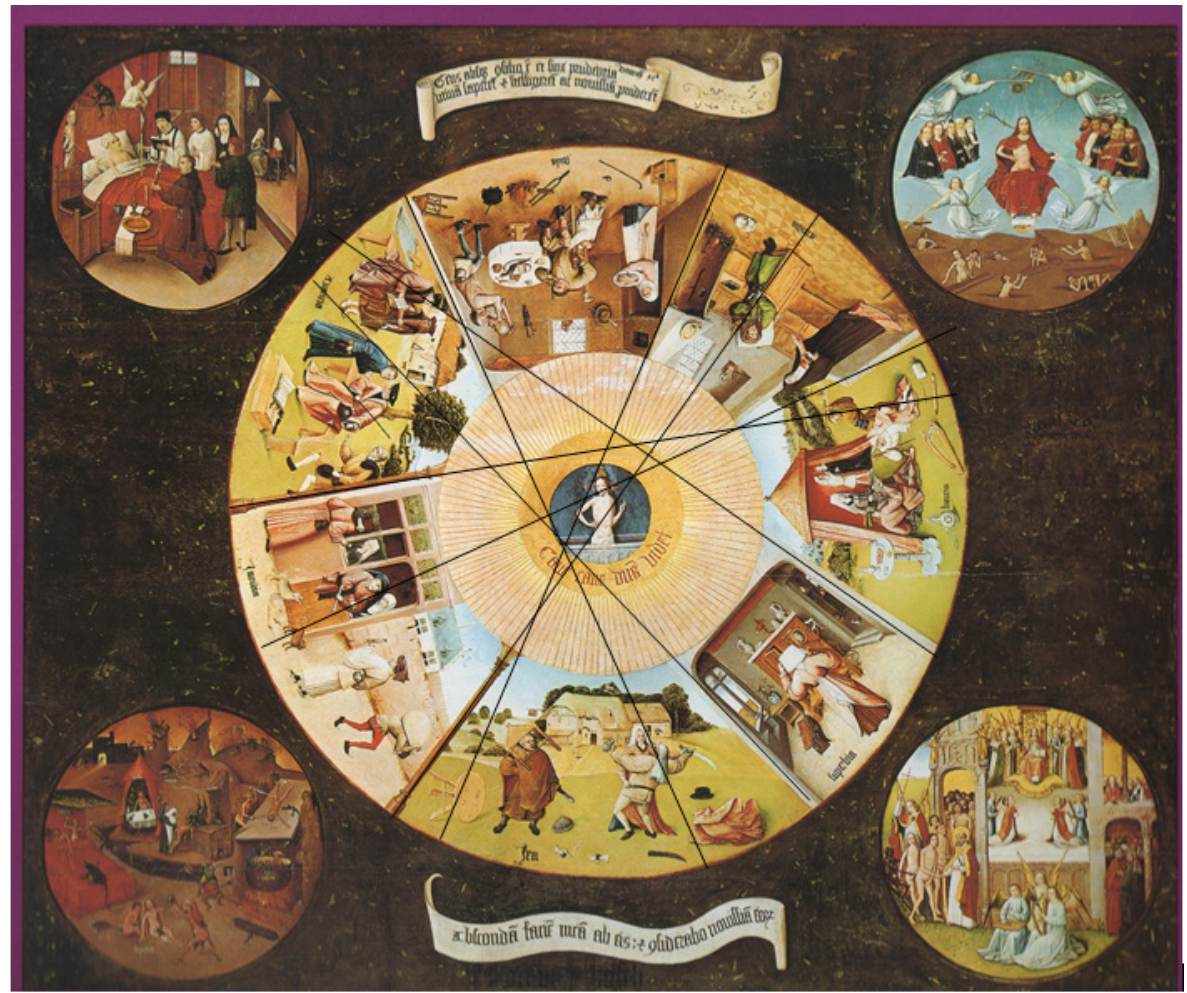

El Bosco, Tabla de los pecados Capitales (1505-1510). Óleo sobre madera de chopo. Medidas: 119, $5 \mathrm{~cm}$ x 139, 8 cm. Ubicación: Museo del Prado. Madrid.

Desde el punto de vista de un análisis formal, se trata de una disposición concéntrica y simétrica. Pues si tomamos el ojo central donde está Cristo y los rayos, las fugas de las radiales del ojo de Dios son convergentes en el centro del círculo; a su vez, el ojo está compuesto por tres anillos al que lo rodea el anillo de los siete pecados. En total,
1. Dramaturgia y dirección: Rafael Spregelburd. Intérpretes: Paloma Contreras, Analía Couceyro, Javier Drolas, Pilar Gamboa, Andrea Garrote, Santiago Gobernori, Guido Losantos, Mónica Raiola, Lalo Rotavería, Pablo Seijo, Alberto Suárez, Diego Velázquez y Rafael Spregelburd. Vestuario: Julieta Álvarez. Escenografía e iluminación: Santiago Badillo. Diseño audiovisual: Pauli Coton, Agustín Genoud. Música original: Nicolás Varchausky. Asistencia de escenografía: Isabel Gual. Asistencia de dirección: Juan Doumecq. Producción: Yamila Rabinovich, Ana Riveros. Colaboración artística: Gabriel Guz. 
tenemos cuatro círculos a los que hay que sumarle los cuatro círculos de las postrimerías en cada una de las esquinas: la muerte (arriba a la izquierda), el juicio final (arriba a la derecha), el infierno (abajo a la izquierda) y el cielo (abajo a la derecha).

Esta disposición de las imágenes obliga al espectador a rodear la tabla para poder ver cada una de las escenas, pero solo la de los pecados; el resto está dispuesto para una vista frontal directa como un cuadro de pared, tal como se leen también las cartelas que citan al Deuteronomio y que advierten a los desobedientes. Desde el punto de vista formal, por su disposición en el cuadro, el pecado más destacado es el de la ira, pues el único que permite una visión a primera vista sin girar, coincidiendo con la vista frontal del círculo triple central (el ojo de Cristo) y los cuatro círculos de las postrimerías. Se puede considerar el principio y el fin del recorrido de los siete pecados, si el espectador se coloca frente al ojo de Dios para iniciar el recorrido circular. El resto de los pecados capitales requieren de un desciframiento a través de un recorrido que circunvala el centro. Y, en este anillo, las líneas radiales que dividen los espacios que ocupa cada uno de los pecados son, por oposición a los radiales del ojo de Dios, excéntricas, no fugan en un centro ni en el centro del ojo de Dios, simbolizan el alejamiento de Dios, el desorden o el caos.

Ahora bien, si quisiéramos ubicar a La Terquedad dentro del universo de la Heptalogía de Spregelburd, el pecado sobre el que está basada es justamente la ira, de forma tal que, al igual que en el cuadro del pintor flamenco, La Terquedad cierra el círculo de los siete pecados. Y si tenemos en cuenta lo que dice el mismo autor, que el centro de su Heptalogía es el lenguaje, podremos reconocer que el centro de La Terquedad, dado por el conflicto de la imposición del lenguaje inventado por el protagonista, se relaciona con el conjunto de la saga.

Partimos de interpretar la noción de terquedad que tematiza la obra como ese sinsentido de Planc de buscar obstinadamente un sentido a través de la invención de una lengua artificial y universal que anule las diferencias, basada en el número, una desmesura, una nueva Babel, que termina generando el conflicto central de la obra. El Katak, como el mismo Planc declara, pretende acercarse al pasado utópico del hombre en donde todavía no había ocurrido la invención del lenguaje, donde existía un habla sin lengua considerada "facultad divina":

Planc: Lo sé. Pero estos son tiempos de grandeza. Los hombres tal como nos creó Dios no teníamos lenguaje. Este invento vino después. Pero Dios nos dotó de un habla sin lengua, de la capacidad de transar pieles sin decir esta boca es mía. Mi trabajo es devolverle al hombre esa facultad divina.

Dimitri: Pensé que su trabajo era de policía. [Acto I, Escena 17]

(Spregelburd, 2009: 50).

De hecho, el Acto I y II empiezan con el ruido de un cuerno a lo lejos, mientras que el Acto III comienza no sólo con el sonido del cuerno, sino con una escena en la que dos hombres primitivos sin hablar representan una transacción comercial de trueque. Así, se puede entender que la compleja trama de la obra está construida de forma tal que inicia y termina con el hombre primitivo, con la negación de la lengua, también de la artificial inventada por Planc, ese alfabeto numérico propuesto como solución a la multiplicación caprichosa que cada idioma hace de sus palabras. Entendemos, pues, que esta estructuración circular de la fábula sostiene y construye el sentido de la obra que descansa sobre una noción de lenguaje sin relación con el mundo, sólo con la norma de que cada quien pueda construir su sentido según un número: 
Planc: (...) había dado con la primera clave. Se trata, por ponérselo simple, de crear un alfabeto numérico. Se trata de un sistema intermedio que permita reducir todos los conceptos llamarlos con un número, para que cada hablante pueda construir luego sus equivalencias. [Acto I, Escena 17] (Spregelburd, 2009: 49)

Esta estructuración de la trama se basa en un manejo circular del tiempo llevado a cabo gracias a procedimientos propio de la narración (como la analepsis y la paralepsis). De modo que la acción transcurre en continuas idas y vueltas sobre el mismo núcleo argumental y así se van desplegando múltiples facetas del conflicto básico, de personajes y micro-intrigas que adquieren unidad en la multiplicidad sincrónica de acciones dramáticas y en la reversibilidad de éstas en escena. De forma tal que la obra mantiene la unidad de la fábula, pero a partir de la multiplicidad de recuentos de escenas y secuencias. Estos procedimientos complejizan una acción dramática sencilla, cuya progresión no guarda el orden normal de los acontecimientos en el teatro en el que cada parte engendra necesariamente a la que sigue. Se vigoriza, así, la teatralidad y se acompaña desde lo formal en ese ir y venir sobre el mismo núcleo, la terquedad de Planc.

Si hacemos un breve análisis de la estructuración temporal de la fábula a partir de las relaciones entre el tiempo del discurso escénico, el tiempo de la historia y el de la representación, descubrimos una maravillosa arquitectura basada en el círculo que hace girar la acción en una dinámica que dura tres actos, los cuales se corresponden tanto en el desarrollo de los acontecimientos cuanto en el desarrollo del tiempo.

En primer lugar, para hacer un análisis del tiempo en el teatro o del tiempo escénico reconoceremos y distinguiremos tres niveles estrechamente relacionados, que se pueden separar teóricamente, pero que, en última instancia, el espectador percibe como una unidad. Estos son: el tiempo de la representación, que consiste en la duración de la puesta en escena y que coincide con el tiempo del público en el teatro; el tiempo de la historia que corresponde al de la fábula y, finalmente, el tiempo del discurso o del discurso escénico, que es la organización temporal con que se presente en escena. El tiempo de la historia y el tiempo del discurso escénico, en general, no coinciden, ya que habitualmente el de la historia es más amplio que el del discurso escénico y queda asumido aquél (el de la historia) en este (en el escénico). Para analizar las relaciones entre el tiempo de la historia y el tiempo del discurso escénico, proponemos las categorías desarrolladas por Genette (1972: 192) en la narrativa: orden, ritmo y frecuencia. De acuerdo con ellas, el orden, tanto del tiempo de la historia como del discurso escénico, pueden sufrir analepsis, prolepsis o elipsis. El ritmo, en el caso del teatro, está dado por el diálogo directo y la frecuencia determina un discurso singulativo, reiterativo, iterativo, anafórico, mientras que la duración de la puesta en escena está determinada por el tiempo de la representación. Ahora bien, si analizamos el discurso escénico de La Terquedad, debemos hacer notar que, gracias a la puesta en escena sobre un espacio escénico dominado por el escenario giratorio y el uso de proyecciones fílmicas, la representación de la obra permite que la estructuración de la fábula, caracterizada por un uso narrativo del tiempo, vuelva una y otra vez la acción al principio en cada uno de los tres actos. Así, Spregelburd logra evitar la progresión temporal creciente de los actos hacia el final propia del teatro clásico y construye un relato escénico acronológico, en la medida en que se ponen en escena los acontecimientos de la trama de tal forma que cada acto ocupa casi el mismo tiempo ficticio y, a la vez, cada uno representa todo el decurso de la acción; es decir, en cada acto asistimos al inicio de la fábula, a la percepción del conflicto central y al final frustrado de la historia, con la salvedad de que cada acto va revelando algunos acontecimientos necesarios para conocer otros detalles de la fábula y la causalidad. En efecto, el escenario gira de un acto a otro y el espectador asiste a la representación de la misma trama, pero viendo esta vez nuevos tramos de acción que ocurrían paralelamente en el acto anterior en el espacio latente. 
La primera observación debe tener en cuenta que la obra y la puesta en escena de la obra señalan el tiempo con reiteradas precisiones temporales que son absolutamente necesarias para la comprensión de los acontecimientos de la fábula. Así, el Acto I comienza a las diecisiete horas, información que de la didascalia del texto dramático pasa a la escena con la proyección fílmica de un reloj que marca la hora. Termina a las dieciocho horas y trece minutos. El Acto II empieza también a las diecisiete horas, pero termina a las dieciocho horas y ocho minutos. Mientras que el Acto III empieza temporalmente antes que los otros dos, a las dieciséis horas y cincuenta y nueve minutos y finaliza, junto con la obra, a las dieciocho horas y catorce minutos, un minuto después de que finaliza el Acto I y seis minutos después del Acto II. Por lo tanto, empieza antes que los otros dos actos y termina después, incorpora a los dos anteriores. Además, si tenemos en cuenta estas precisiones temporales, los acontecimientos de la trama en escena tienen una duración de una hora y quince minutos y configuran el tiempo ficticio representado, por más que la fábula incluye el relato de antecedentes temporales que extienden el origen de la historia hasta algunos años atrás.

Destacamos fundamentalmente tres momentos y acciones que se repiten en cada uno de los tres actos y que, a la vez, marcan el inicio, el medio y el final de la historia o fábula. Los tres actos repiten un mismo inicio, no sólo marcado por la exactitud de la hora (Acto I: 17 h.; Acto II: 17 hs.; Acto III, 16.59 hs.), sino por la repetición de algunas acciones importantes que constituyen un relato marco: como señalamos antes, el Acto I y II empiezan con el ruido de un cuerno a lo lejos; mientras que el Acto III, además del sonido del cuerno, incorpora la escena de los dos hombres primitivos que sin hablar representan la transacción comercial de trueque. Así, al final, el espectador entiende el porqué del sonido de los cuernos al inicio de cada uno de los otros dos actos anteriores y puede reconstruir el relato marco. La prehistoria de la acción dramática es, pues, un conflicto prehistórico resuelto sin mediación del lenguaje verbal, por señas, acciones cuya única conexión con la fábula central es la idea de la ausencia del lenguaje o su incapacidad para comunicar y otorgar sentido, idea que, por otra parte, se desprende del sentido que adquieren las acciones escénicas y los parlamentos de Planc, cuando justifican su obsesión por crear una lengua numérica.

Luego tomamos una escena, la once, que comienza a las diecisiete horas y treinta y dos minutos y que se encuentra a la mitad respecto de la duración del tiempo escénico y de la acción dramática si tenemos en cuenta el criterio de la cantidad de escenas que contiene cada acto y las precisiones del tiempo (ya que el primer acto tiene un total de veintidós escenas; el segundo, diecinueve y el tercero, veintitrés). Constatamos que, a esta altura de la acción dramática, el Acto I, el II y el III coinciden no sólo en que en los tres casos la escena once se inicia a las 17.32 horas, sino que resulta significativo que se repitan los siguientes parlamentos:

Acto I, Escena 11, hora 17.32 (espacio escénico: la sala de la casa de Planc):

Antoni: Eso es relativo. Su padre es comisario, sí, pero así es como también fue

funcionario de un gobierno republicano.

Alfonsa: Tanto como usted editor

Planc: (Entrando dese el jardín)...de un país que probó un rato de república.

Acto II, Escena 11, hora 17.32:

Hacen silencio. Escuchan parte de la conversación de la sala

Alfonsa: (en la sala) Tanto como usted editor

Planc: (en la sala) ide un país que probó un rato de república

Acto III, Escena 11, hora 17.32:

Sanchís: ¿Tu piensas que Antoni tiene realmente interés en tu hija? 
Planc: Eso espero. Óigalo, está hablando de mí (Deja la lista. Escucha junto a la puerta. Decide entrar, justo a tiempo para completar la frase de Alfonsa)

Alfonsa: (Dentro) Tanto como usted editor...

Planc: (Entrando)... ide un país que probó un rato de república!

Esta repetición y la coincidencia temporal en el centro de la distribución de las escenas de cada uno de los tres actos resalta la anécdota central, la cuestión política e ideológica de la guerra civil española sobre la que se tejen los conflictos personales del protagonista y del resto de los personajes. Y marca también la unidad de la fábula la que, a pesar de todo, mantiene sus elementos entrelazados y permite la comprensión de la intriga y una expectación unitaria, por más que la obra deje algunos cabos sueltos, como por ejemplo el personaje de Fermina, que entra y sale de las escenas sin mucha coherencia narrativa.

Luego, destacamos el final de cada uno de los tres actos y de la pieza en general: el Acto I termina ya con el fracaso de Planc en su plan de presentar su diccionario para que el editor ruso lo publique y se difunda por el mundo la creación de su nueva lengua artificial. No sabemos qué pasó exactamente, pero salen de la habitación de Alfonsa, Planc y el editor ruso, Dimitri. Planc muy consternado, Dimitri muy entusiasmado y con el maletín del que brotan muchos billetes. Luego Planc sale al jardín (Acto I, escena 19). En la escena 20 se produce un agón entre Sanchís y Dimitri en el cual Sanchís le reprocha haber acabado con el proyecto del diccionario de Planc. La escena 21 es un diálogo entre Natalie, la sirvienta francesa, y Dimitri en donde hablan de la libertad, ya que Dimitri lamenta que ella sea sirvienta, porque en su país sería libre.

Y, finalmente, en la escena 22, entra Planc desde el jardín con un garrote en la mano fuera de sí y tiene un pequeño diálogo con Dimitri en el cual le pide que se retire de su casa. No sabemos exactamente qué pasó antes en la habitación de Alfonsa, donde fueron con el fin de que Planc hiciera una demostración de su diccionario. Es decir, no sabemos por qué fracasó la idea de Planc, pero finaliza con este fracaso y con el enojo del comisario.

El Acto II se desarrolla íntegramente en la habitación de Alfonsa: comienza a la misma hora que el primero y se desarrollan acontecimientos isocrónicos con respecto a la escena anterior. De hecho, empieza de igual forma, con el sonido del cuerno, y luego muestra algunos otros conflictos interrelacionados con la trama principal: un inglés que viene a buscar la lista de los revolucionarios para salvarlos y está escondido y amenazando a Alfonsa para que se la consiga; Fermina, hija del comisario del Estado franquista, se alía con el inglés que apoya la revolución; el padre Francisco, quien a pesar de que se presenta como un remedio para curar la enfermedad de Alfonsa, muestra su deseos carnales para con la muchacha. Finalmente, en las escenas dieciocho y diecinueve, asistimos a la prueba que hace Planc a Dimitri sobre su nueva lengua y su descubrimiento, el porqué del enojo de Planc y el fracaso de su proyecto inicial. Dimitri le ofrece dinero a cambio de que le entregue el prototipo para llevarlo a Moscú. Planc se ofende.

El Acto III desarrollado en el jardín de la casa, y con un comienzo anticipado en un minuto respecto de los otros dos, muestra algunas reiteraciones y nuevas facetas de la composición de la trama de las acciones: la verdadera historia de por qué Planc se separa de su esposa anterior, Magda, y se casa con Nuria, el hecho de que él sigue enamorado de Magda y de que ella no quiere tampoco a su actual marido, la historia de la lista de los revolucionarios que busca Magda, porque sospecha que su marido actual está allí. Al final, en la escena veintidós, Natalie, la sirvienta francesa, sale al jardín y mata a su primera víctima, Dimitri, sin ninguna razón, porque está loca, solo que nadie lo había notado, porque no hablaba bien la lengua y cuenta en francés: 
"Un" En la escena siguiente y última, ella mata a Arribau con otro disparo, mientras cuenta en francés: "deux". Luego ingresa a escena Alfonsa contra quien también dispara. "Trois", cuenta. Cuando Planc se abalanza sobre su hija, le dispara también a él aunque no lo mata. "Quatre". Entra después Riera y Natalie nuevamente dispara matándolo, con la bala número "Cinq", aunque no la cuenta e intenta nuevamente disparar contra Planc para terminar con él, pero se queda sin balas. La obra finaliza con Planc y Natalie en escena en gran estado de confusión:

Se ha olvidado de contar la bala con la que mató a Riera. Ninguno de los dos se mueve. Ella baja lentamente el brazo, no sabe qué hacer. Planc tampoco. Cae de rodillas agobiado. Se echa a llorar, se agarra la herida en el brazo. Natalie deja caer el arma, lentamente, y se sienta en una silla de jardín, a capturar los últimos rayos del sol de la tarde de invierno. Toma una de las hojas desparramadas por Dimitri. La lee. Toma una segunda hoja. La lee. Toma una tercera. La luz baja muy lentamente sobre ellos. (Spregelburd, 2009: 129. Didascalia que marca el fin de la obra)

En consecuencia, el tiempo ficticio abarca una hora y quince minutos en total, aunque se desarrolla en cada uno de los tres actos de principio a fin con algunas irregularidades como la hora de finalización y como la duración del tiempo de representación de cada uno de los tres actos, ya que el tiempo de la representación duplica al ficticio. Se niega, así, el carácter sucesivo de los acontecimientos y su linealidad temporal. De forma tal que, con una disposición de los acontecimientos al interior de cada uno de los actos a partir de un estricto orden cronológico y con cantidad de tiempo ficticio que es igual, se construyen tres actos que no tienen la misma duración. Además, el ritmo, dado por el diálogo directo, si tenemos en cuenta que algunos se repiten y superponen, por momentos se vuelve reiterativo, anafórico. La obra descansa, así, sobre un principio de irregularidad disfrazada de regularidad y contribuye a destacar el desvío, la falta de linealidad, el desfasaje temporal que, por otra parte, también es tematizado por la propia obra. En efecto, como dice Planc ante el fracaso de su diccionario de la lengua artificial y tras recibir una carta de su hijo enviada desde el frente de combate que llega después de su muerte:

Planc: Yo pensé que la lengua más perfecta era la que iba a arrancar todas las palabras de la oscuridad de ese pozo. Pobre Rebeca, pobres hijos míos. Pensé que el tiempo pondría fin a mi desdicha. Pero el tiempo no viaja nunca hacia adelante. Eso es un mito. El tiempo solo sabe girar en círculos. Hasta que yo le ponga fin. Toma el garrote y entra a la sala. (Spregelburd, 2009: 125)

Este parlamento resulta, pues, un enunciado de la idea sobre la que descansa el discurrir del tiempo en la obra. Así, cada acto contiene a la obra completa en sí misma con mínimas diferencias, con ampliaciones y repeticiones del mismo conflicto central. Y cada acto termina de igual forma, casi sobre la misma hora, es decir que cada instancia es un continuo comenzar y terminar. Como dice el comisario "el tiempo solo sabe girar en círculos", como la obra misma, como un ouroboros que obstinadamente, tercamente, se muerde la cola.

A la vez este orden acronológico general de la obra, basado en la cronometrización de los acontecimientos al interior de los actos, resulta una especie de oxímoron que produce una fragmentación y una diseminación de las partes de la fábula. Pues aparece recortada en una serie de fragmentos que producen sentido en una especie de idas y vueltas sobre el punto de inicio, pero que, en última instancia, esta relación entre forma y contenido de la obra, apunta a la incertidumbre, a la ausencia de límite, como procedimiento central de composición de La Terquedad, tal como el mismo autor lo declara en la entrevista hecha por Dubatti para la edición de la obra: 
Es, en todo caso, bastante evidente que La Terquedad opera sobre el principio físico y retórico de la incertidumbre (...) ¿Es John un fantasma? ¿Por qué tardamos tanto en comprender quién es Rebeca? ¿Sabrá el padre Francisco que John no se ha llevado su llave? ¿Quién es el verdadero destinatario del diccionario de Planc? ¿Cómo es posible que un hombre que ha inventado un objeto formidable (por ejemplo, una computadora, en 1939) crea haber inventado otra cosa? ¿Cómo termina esta obra? ¿Qué pasará en los cinco minutos siguientes a la caída del telón? El procedimiento de construcción más profundo de la obra-aquel que puedo ver con cierta distancia- supone de algún modo el pesimismo como única mirada. (Spregelburd en Dubatti, 2009: 141)

En fin, si tenemos en cuenta la relación entre el manejo del tiempo de la historia o fábula y el tiempo del discurso escénico, observamos una frecuencia dominada por un discurso iterativo y anáfórico, un discurso terco que vuelve sobre sí mismo. A la vez, la obra propone una singular mirada espectorial teatral, muy cercana a la experiencia narrativa o fílmica, y la circularidad de la trama al proceso de observación que requiere la tabla de los pecados de El Bosco. Además, la diseminación de las partes de la fábula en estos ritournelles y en la multiplicidad de lenguajes artísticos en escena (proyecciones, pinturas y música) construye una teatralidad atravesada por el procedimiento de la epicización del drama y por el aporte de otros lenguajes artísticos. La trama finaliza con el fracaso del Katak y con la catástrofe final de la obra, con la muerte de casi todos los personajes debido al sin sentido, a la criada que era loca y que, en un acto demencial, mata a casi todos. La ira se manifiesta así en la obra junto a la locura y al sin sentido que opera drásticamente sin que se pueda hacer nada para detenerla. Porque en última instancia nadie se da cuenta de la locura de Natalie, porque justamente habla otro idioma y nadie le entendía correctamente. El problema finalmente es la multiplicidad de las lenguas que no permite la comunicación, algo contra lo que no pudo Planc ni su idea de crear una lengua que sólo contenga conceptos útiles:

Dimitri: A eso voy. Deduzco entonces que su lengua sólo contiene los conceptos que son útiles

Planc: Definitivamente.

Dimitri: ¿Y quién juzgará la utilidad de las palabras?

Planc: Yo y la historia.

Dimitri: Está una ambición muy grande.

Planc: Lo sé. Pero estos son tiempos de grandeza. Los hombres tal como nos creó Dios no teníamos lenguaje. Este invento vino después. Pero Dios nos dotó de un habla sin lengua, de la capacidad de transar pieles sin decir esta boca es mía. Mi trabajo es devolverle al hombre esa facultad divina.

Dimitri: Pensé que su trabajo era de policía. (Spregelburd, 2009: 50 Acto I, Escena 17)

La obra termina con la prehistoria, con el primitivo o el loco dominando la escena. El desorden destruyó el orden perfecto y numérico global que pretendía Planc. Porque, en última instancia, no sólo fracasó la invención del nuevo idioma, sino también la realidad de Planc. Y, con ella, fracasa el intento globalizador de la sustitución de las fronteras idiomáticas, geográficas, culturales, etc. Sin embargo, la misma acción dramática central conlleva el germen de su contrario, el triunfo de la ausencia de lenguaje por el acierto en la transacción de los hombres primitivos, la cual termina siendo una cuestión de números, de cantidades en la medida en que uno de los cavernícolas cambia una piel trabajada por dos en bruto. Las cantidades, los números de los que hablaba Planc, dominan en ese espacio-tiempo primitivo del origen, pues el número termina con las diferencias. En efecto: 
Spregelburd elide las letras y prefiere los números, allí no hay margen de error, la ambigüedad queda en la interioridad de cada sujeto. Ese lenguaje nos da las bases también de la informática, de la computación. La Terquedad sueña con un fascista que encontró, sin darse cuenta, el lenguaje computacional (Crítico Enmascarado, consultado el 7 de julio de 2017, en: http://www.actualidadartistica.com.ar/2017/03/ la-terquedad-por-el-critico-enmascarado.html)

Y, en verdad, el interrogante planteado por la crítica sobre el anhelo fundamentalista de anular las diferencias mediante el Katak, que se presenta en realidad como prefiguración del lenguaje binario de la computadora, es una de las cuestiones más importantes que plantea la obra. De hecho, la computadora aparece en la puesta en escena ya que, en el Acto II cuando Planc lleva a Dimitri al cuarto de Alfonsa para hacerle la demostración de su nuevo diccionario, lo que le muestra es el CPU de una computadora, pero el protolenguaje binario fracasa junto con el Katak. Es decir, la historia unitaria que cuentan las tres escenas fracasa, salvo el pequeño relato marco, que se abre con el sonido del cuerno al inicio de la historia y se cierra con el éxito de la transacción entre hombres primitivos; es decir, tiene éxito el único relato que guarda el orden cronológico de los acontecimientos en el teatro. De modo que esta doble trama, en donde la de los hombres primitivos no es más que una pequeña escena, construye en La Terquedad una suerte de epillyon, en donde el relato marco y el central funcionan en conjunto, adquieren sentido uno junto al otro. El relato marco impregna de sentido el relato central a tal punto que general al final una relectura de la obra. El Katak fracasa mientras que la transacción primitiva basada en el número se realiza con éxito; lo útil triunfa sobre la proliferación descontrolada de sentidos. En última instancia, el anhelo de Planc, la devolución al hombre de la capacidad ¿divina? de habla sin lengua triunfa y, con ella, lo particular (el habla) sobre lo universal. 


\section{Q Bibliografía}

》 Bobes, M. del C. (1997). Semiología de la obra dramática, Madrid, Arco/Libro.

"Crítico Enmascarado (2017). "El idioma análitico de R. Spregelburd”. Actualidad artística [en línea]. Consultado el 7 de julio de 2017, en: <http://www.actualidadartistica.com.ar/2017/03/la-terquedad-por-el-critico-enmascarado.html >

"Dubatti, J. (2009). "Entrevista con Rafael Spregelburd para la publicación de La Terquedad". En Rafael Spregelburd, La Terquedad, Buenos Aires, Adriana Hidalgo.

»Gender, S. (2008). "Parodia en la Heptalogía de Hieronymus Bosch de Rafael Spregelburd”. Boletín Hispánico Helvético 11, 163-182.

» García Barrientos, J. L. (2012). Cómo se comenta una obra de Teatro, México, Paso de Gato.

» Genette, G. (1972). Figuras III, España, Lumen.

"Spregelburd, R. (2009). La Terquedad, Buenos Aires, Atuel/Teatro. [Apéndice documental y edición al cuidado de Jorge Dubatti]. 